\title{
$\beta$-Nerve Growth Factor in Developing Mouse Cerebral Cortical Synaptosomes: Measurement by Competitive Radioimmunoassay and Bioassay
}

\author{
J. LAKSHMANAN, M. E. WEISCHEL, JR, R. TARRIS, AND D. A. FISHER \\ Department of Pediatrics, Harbor-UCLA Medical Center, Torrance, California 90509
}

\begin{abstract}
The existence of $\beta$-nerve growth factor $(\beta N G F)$ in mouse cerebral cortical synaptosomal extracts was assessed using a newly developed radioimmunoasay and by bioassay. Displacement curves of labeled $\beta$ NGF in the radioimmunoassay by synaptosomal extracts were parallel to the $\beta$ NGF standard curves. In contrast, both mitochondrial and nonsynaptosomal extracts produced displacement curves in the $\beta$ NGF radioimmunoassay which were nonparallel to standard $\beta$ NGF. Intraventricular injections of purified $\beta$ NGF in amounts 5 and $100 \mathrm{ng} /$ mouse (six to 120 times that of whole brain $\beta$ NGF concentrations) did not alter the endogenous synaptosomal $\beta$ NGF concentrations. Synaptosomal extracts contained $\beta$ NGF in relatively higher concentrations than the extracts of whole brain or cerebral cortex. Synaptosomal $\beta$ NGF levels undergo a developmental change. The $\beta$ NGF concentrations were highest in synaptosomal extracts of 12-day-old mouse cerebral cortex (the youngest age studied), and levels decreased with increasing age. Synaptosomal extracts of 12-day-old mouse cerebral cortex produced neurite outgrowth in the pheochromocytoma cell line 12 bioassay system and this response was completely inhibited by $\beta$ NGF antibodies. In the pheochromocytoma cell line 12 cell bioassay, synaptosomal extracts also caused cell-cell aggregation which was unaffected by $\beta$ NGF antibodies. These results provide evidence for the existence of $\beta \mathrm{NGF}$ in relatively high concentration in nerve terminals of mouse cerebral cortex. (Pediatr Res 20: 391-397, 1986)
\end{abstract}

Abbreviations

$\beta$ NGF, $\beta$-nerve growth factor

NGF, nerve growth factor

PC-12, Pheocromocytoma cell line 12

RIA, Radioimmunoassay

CNS, Central nervous system

SE, Synaptosomal extract

NGF is a protein involved in the life cycle of neurons of the fetal, neonatal, and adult autonomic nervous system $(1,2)$. When NGF is introduced in vivo or in suitable in vitro culture systems, it elicits a variety of morphological and biochemical changes in noradrenergic neurons of sympathetic ganglia (3). NGF also elicits similar biological responses in mediodorsal neurons of sensory ganglia of peripheral nervous system (4). Conversely,

Received July 9, 1985; accepted November 18, 1985.

Correspondence Dr. J. Lakshmanan, Center for Neurologic Study, 11211 Sorrento Valley Road, Suite H, San Diego, CA 92121

Supported by NIH Grants HD-11303 (M.E.W.), HD-04270 (D.A.F.), and NS17431 A (J.L.).
NGF-antiserum disrupts the ultrastructure and impairs several biochemical functions leading to the death of the target neurons (5-7). These results provide unambiguous evidence in support of a survival and maintenance role for NGF in neurons of the peripheral nervous system.

In contrast, the nature of NGF target neurons in the CNS is not clear. The findings that exogenous NGF stimulates regenerative growth of central noradrenergic neurons and that anti-NGF inhibits this NGF-stimulated regenerative growth indicate that central catecholaminergic neurons may acquire NGF responsiveness during repair and regeneration processes $(8,9)$. Furthermore, recent data indicating the ability of NGF to augment choline acetyltransferase activity in neonatal and adult brain (10-12) and in aggregate brain cell culture systems (13) suggest that cholinergic neurons also may represent NGF-target neurons in the CNS. Retrograde axonal transport of NGF has been described in certain central cholinergic systems supporting the view that NGF may function in adult cholinergic neurons (14, $15)$. Despite the different $\beta$ NGF biological responses, there is considerable controversy regarding the location and amounts of NGF present in the CNS (16-19).

Earlier studies including our own (18) utilized RIA systems developed against NGF purified by conventional methods and NGF purified in this way may contain immunogenic contaminants (20). Therefore, in the present study, we reexamined the presence of NGF in mouse brain and cortex using a newly developed NGF-RIA system with a highly sensitive and specific polyclonal antiserum raised against an immunogenically pure $\beta$ NGF preparation. The same highly purified $\beta$ NGF was utilized to produce labeled antigen. In addition, we assayed for $\beta$ NGF in purified cerebral cortical synaptosomes (pinched-off nerve terminals), the organelles reported to be rich in NGF-specific receptors $(21,22)$. Finally, the presence of $\beta$ NGF was validated using a PC-12 neurite outgrowth bioassay system. The results indicate the presence of $\beta \mathrm{NGF}$ in subnanogram concentrations in brain cerebral cortex and cortical synaptosomes.

\section{MATERIALS AND METHODS}

Animals. Time-dated pregnant Swiss Webster mice were purchased from Simonsen Laboratory (Gilroy, CA). On arrival to the Harbor UCLA vivarium, the animals were housed in individual cages and were given standard mouse food and water ad libitum. Pups born within $16 \mathrm{~h}$ of each other were pooled and randomly distributed eight pups per mother. The day of birth is recorded as day 0 . Each litter was housed with its mother in a metal cage with wood shavings for bedding. Animals were inspected daily to guarantee maternal care, and cages were changed three times weekly. The litter size was maintained at eight per dam until the time of weaning. On day 21 , the pups were separated from the mother and maintained thereafter as four weanlings per cage. In studies involving animals older than 21 days of age, only female mice were taken for the experiment. 
All animals were sacrificed by $\mathrm{CO}_{2}$ narcosis which ensured death in less than $1 \mathrm{~min}$. Care was taken during the dissection not to reuse the scissors and forceps used for removal of submandibular glands to carry out the dissections of brain and various brain regions.

Whole brains were removed and placed in a beaker containing $5 \mathrm{ml}$ of $0.32 \mathrm{M}$ ice cold sucrose. Brain tissues were rinsed at least three times with $5 \mathrm{ml}$ of $0.32 \mathrm{M}$ sucrose. During dissection, the whole brain was placed on a piece of glass plate overlying an ice bucket. The cortices were dissected free from adhering corpus callosum with fine forceps and scissor and immediately transferred to a beaker containing $0.32 \mathrm{M}$ ice cold sucrose. Usually 2 to $2.5 \mathrm{~g}$ wet weight of cerebral cortex was pooled and three such pools for each age were individually processed for fractionation studies.

Isolation of synaptosomal fraction. For synaptosomal isolation the procedures described by Gray and Whittaker (23) and later by Levitan et al. (24) were modified as described below. Briefly, pooled cerebral cortical tissues were placed in 9 volumes of 0.32 $M$ sucrose and cut into pieces with a fine scissor. The minced tissue was homogenized (three up and down strokes) gently by hand, and then by a motor driven homogenizer $(400 \mathrm{rev} / \mathrm{min}$, eight up and down strokes). Both hand homogenization and motor driven homogenizations were performed in a glass-Teflon homogenizer with a clearance of $0.25 \mathrm{~mm}$. The homogenates were centrifuged as outlined in Figure $1 \mathrm{~A}$. The P2 pellet was resuspended in $0.32 \mathrm{M}$ sucrose $(5 \mathrm{ml} / \mathrm{g}$ original tissue), layered on a discontinuous sucrose density gradient consisting of equal layers of 1.2 and $0.8 \mathrm{M}$ sucrose (12 ml each) and kept $1 \mathrm{~h}$ before use. Samples then were centrifuged at $75,000 \times g$ for $120 \mathrm{~min}$ in a Beckman ultracentrifuge with a SW 25.1 rotor. The fractions between the 0.8 and $1.2 \mathrm{M}$ sucrose interfaces were removed and
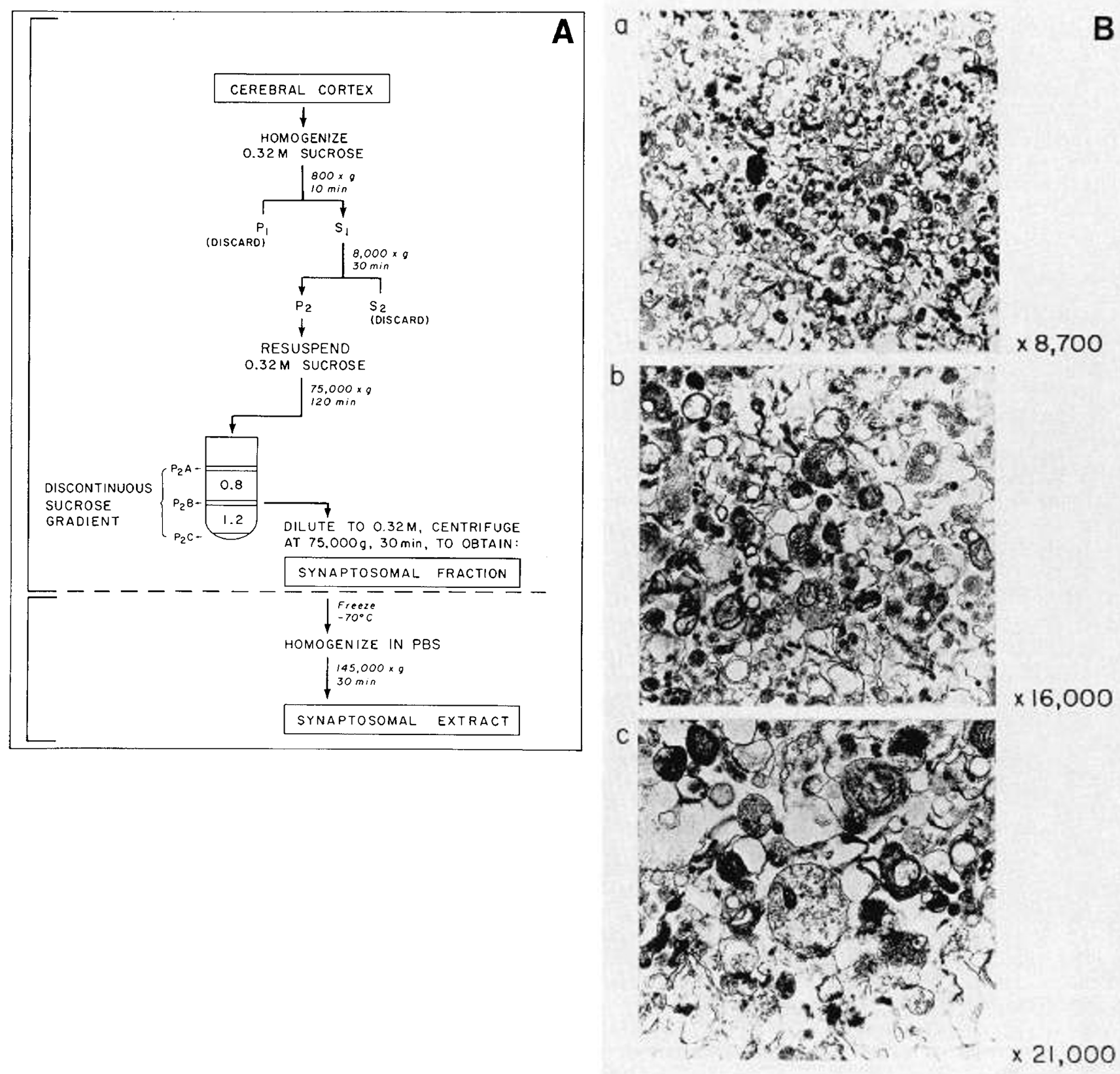

Fig. 1. Isolation of synaptosomes from mouse cerebral cortex. $A$, schematic of the procedure used for isolation of synaptosomes from 26 -day-old mouse cerebral cortex. $B$, synaptosomal to actions as observed by electron microscopy. Magnification, $a=\times 8,700, b=\times 16,000, c=\times 21,000$. See text for other details. 
diluted to $0.32 \mathrm{M}$ sucrose by adding $0.16 \mathrm{M}$ ice cold sucrose solution. The synaptosomal fractions were pelleted by centrifugation at $75,000 \times g$ for $30 \mathrm{~min}$. The supernatant solutions were discarded and the pellets resuspended in $0.05 \mathrm{M}$ phosphate buffered saline $\left(1 \mathrm{ml} / 2 \mathrm{~g}\right.$ original tissue) and frozen at $-70^{\circ} \mathrm{C}$ overnight. On the following day, the samples were thawed, transferred to a glass homogenizer, and homogenized (10 up and down strokes). The samples were centrifuged at $145,000 \times g$ for 30 min using a 40.3 rotor. The clear supernatants, referred to as "synaptosomal extract," were used for quantification of $\beta$ NGF. Protein content was measured by the method of Lowry et al. (25).

Extraction of mitochondrial-rich fractions. For comparative purposes, we also extracted the P2C pellet (mitochondrial-enriched fraction) obtained from the discontinuous sucrose density gradient centrifugation. Homogenization and extraction were performed as described for the synaptosomal fractions.

Isolation of "nonsynaptosomal" fraction. For studies of "nonsynaptosomal fractions," pooled cerebral cortices were subjected to initial homogenization in $0.25 \mathrm{M}$ sucrose, a suboptimal condition for obtaining synaptosomal fractions. The $10 \%$ homogerate prepared in $0.25 \mathrm{M}$ sucrose was centrifuged as outlined in Figure $1 A$ for isolation of synaptosomal fractions.

Isolation of synaptosomal fraction after intraventricular injection of $\beta N G F$. To assess the extent of possible artifact in the measurement of synaptosomal $\beta \mathrm{NGF}$ concentrations, experiments were performed in animals that received intraventricular injections of purified $\beta$ NGF preparation. The specific landmarks for intraventricular injection were standardized by injecting $3 \mu \mathrm{l}$ of India ink and studying the spread of the ink in animals sacrificed at different times. For these experiments, 21-day-old animals of similar body weights were chosen. In experiment 1 , mice were injected intraventricularly with $5 \mathrm{ng} \beta \mathrm{NGF}$ dissolved in $3 \mu \mathrm{l}$ of saline; in experiment $2,100 \mathrm{ng} \beta \mathrm{NGF}$ were injected in $3 \mu \mathrm{l}$ of saline. Animals were sacrificed $16 \mathrm{~h}$ after the injection. Cerebral cortices were separated and synaptosomal fractions isolated as described in Figure $1 \mathrm{~A}$.

Electron microscope technique. The fractions collected at the interface of $0.8 \mathrm{M}$ and $1.2 \mathrm{M}$ sucrose solutions were diluted with 10 volumes of $2.5 \%$ glutaraldehyde, $\mathrm{pH} 7.3$, in $0.1 \mathrm{M}$ sodium cacodylate buffer. The mixture was centrifuged at $50,000 \times g$ for 30 min using a SW25.1 rotor. The supernatnat was discarded. The pellets were washed three times with $5 \mathrm{ml}$ of the above buffer, and postfixed in buffered $1 \%$ osmium tetroxide for 30 min at $4^{\circ} \mathrm{C}$. Pellets were dehydrated and embedded in Epon. Sections stained with toluidine Blue were cut at various levels and examined in a Hitachi H1-11E electron microscope. Photographs were taken from the entire thickness of the pellet.

$\beta N G F$ RIA. The $\beta$ NGF antiserum used in the present study was developed in a rabbit by repeated intradermal injections of mouse submandibular gland $\beta$ NGF prepared according to the method of Mobley et al. (26) as modified by Chapman et al. (27). The same purified $\beta$ NGF was iodinated by the chloramine $\Upsilon$ method of Greenwood et al. (28). Labeled $\beta$ NGF was purified as described in Grueters et al. (29). The specific activity of ${ }^{125} \mathrm{I}$ $\beta$ NGF determined by self displacement assay was $5.3 \times 10^{6} \mathrm{Ci} /$ mol. The antiserum bound $50 \%{ }^{125} \mathrm{I}-\beta \mathrm{NGF}$ at a final dilution of $1: 250,000$. Binding affinity of the antiserum for $\beta N G F$ was estimated by Scatchard analysis. There were two populations of antibodies with $\mathrm{Kd}$ values of $7.6 \times 10^{11}$ and $7.0 \times 10^{10} \mathrm{~mol} / \mathrm{liter}$. The mean Kd determined by Lineweaver-Burk plot was $1.7 \times$ $10^{11} \mathrm{~mol} /$ liter. The RIA was performed using a liquid phase double antibody method. The buffer and assay protocol were as described by Walker et al. (30), except that $1 \mathrm{~h}$ after the addition of goat antirabbit immunoglobulin, $60 \mu \mathrm{l}$ of $25 \%$ polyethylene glycol 8000 (J. T. Baker Chemical Co., Phillipsburg, NJ) was added. One hour later the tubes were centrifuged at $2500 \times g$ for $30 \mathrm{~min}$. The supernatants were aspirated and the precipitate counted in a well type $\gamma$ spectrometer. The RIA system showed no cross-reaction with ovine growth hormone, ovine prolactin, rat growth hormone, porcine relaxin, oxytocin, vasopressin, glucagon, insulin, submandibular gland renin, angiotensin II, or epidermal growth factor when tested at maximal concentrations of $1 \mu \mathrm{g} /$ tube. The least detectable concentration of $\beta \mathrm{NGF}$ (defined as the point at which $10 \%$ displacement of ${ }^{125}-\beta$ NGF by unlabeled $\beta$ NGF was achieved) consistently ranged from 16 to $21 \mathrm{pg} /$ tube. Nonspecific binding was consistently less than $6 \%$. Inter- and intraassay coefficients of variation were 5 and $6 \%$, respectively.

PC- 12 cell bioassay. PC- 12 cells were cultured in medium consisting of $85 \%$ RPMI-1640 medium supplemented with $10 \%$ horse serum and $5 \%$ fetal calf serum, $100 \mu \mathrm{g} / \mathrm{ml}$ streptomycin, and $150 \mathrm{U} / \mathrm{ml}$ penicillin. For the neurite bioassay, cells maintained in log phase growth were washed with Ham's saline B and resuspended in RPMI buffer containing 3\% horse serum. Aliquots of cells were cultured in the presence of synaptosomal extracts in the absence or presence of purified $\beta$ NGF antibody. The bioassays were carried out in six well cluster dishes (Costar, Van Nuys, CA). Cells were inspected at the end of $24 \mathrm{~h}$ for a neurite outgrowth response.

Statistical analysis. All data were expressed as mean \pm SEM. RIA parallelism was assessed by measurement of $\beta \mathrm{NGF}$ in varying amounts of synaptosomal extracts or other fractions to be tested $(15-300 \mu 1)$. The slopes of the regression lines (of percent labeled NGF binding versus NGF standard or volume of test material) were calculated after log-logit transformation and tested for significance using Student's $t$ test. $\beta$ NGF concentrations between age groups were compared using analysis of variance. Individual comparisons after analysis of variance were made using the Newman Keul's test. Significance was assumed at the $5 \%$ level $(p<0.05)$

\section{RESULTS}

The protocol used for isolation of synaptosomal fractions from mouse cerebral cortex is outlined in Figure $1 A$. The quality of synaptosomal fractions isolated at the 0.8 and $1.2 \mathrm{M}$ sucrose interface was assessed by electron microscope examination. Representative micrographs of these interface fractions isolated from 26-day-old mouse cerebral cortex are shown in Figure $1 B$. This fraction was found to be rich in synaptosomes, but small amounts of membrane sacs, isolated endoplasmic reticulum, synaptosomal membrane fragments, and mitochondria also were observed. The origin of membrane fragments and free mitochondria is not clear; they may be of nonsynaptosomal origin or may have arisen from rupture of synaptosomes during preparation.

SEs prepared from 21-day-old mouse cerebral cortices were examined for $\beta$ NGF immunoreactivity. SE, when added in varying amounts, produced RIA displacement curves parallel to the purified $\beta$ NGF standard (Fig. 2, upper panel). The mean slope values for the regression lines generated by standard $\beta$ NGF and synaptosomal extracts were $-1.0 \pm 0.01$ and $-0.96 \pm 0.03$, respectively $(p>0.05)$. Extracts of the mitochondrial-rich fraction, however, produced a nonparallel line in the $\beta$ NGF-RIA (Fig. 2, lower panel). The mean slope values for the regression lines of standard $\beta$ NGF and mitochondrial extracts were $-1.0 \pm$ 0.01 versus $-0.72 \pm 0.02$, respectively $(p<0.05)$.

The existence of immunoreactive $\beta \mathrm{NGF}$ material in synaptosomal fractions was established by isolated 0.8 and $1.2 \mathrm{M}$ sucrose interface organelles following initial homogenization of cerebral cortices in $0.25 \mathrm{M}$ sucrose, a nonoptimal condition for obtaining synaptosomal fractions. For this purpose, half of the cerebral cortices removed from the same animals were homogenized in $0.32 \mathrm{M}$ sucrose solution. Both of the $10 \%$ homogenates were processed as described in Figure $1 A$. Only SE produced a RIAdisplacement line parallel to the $\beta$ NGF standard (Fig. 3). The slope value for the regression line generated by nonsynaptosomal extract was $-0.74 \pm 0.01(p<0.05)$ relative to $\beta$ NGF standard.

Because isolation of synaptosomal fractions involved several hours of homogenization and differential centrifugation proce- 


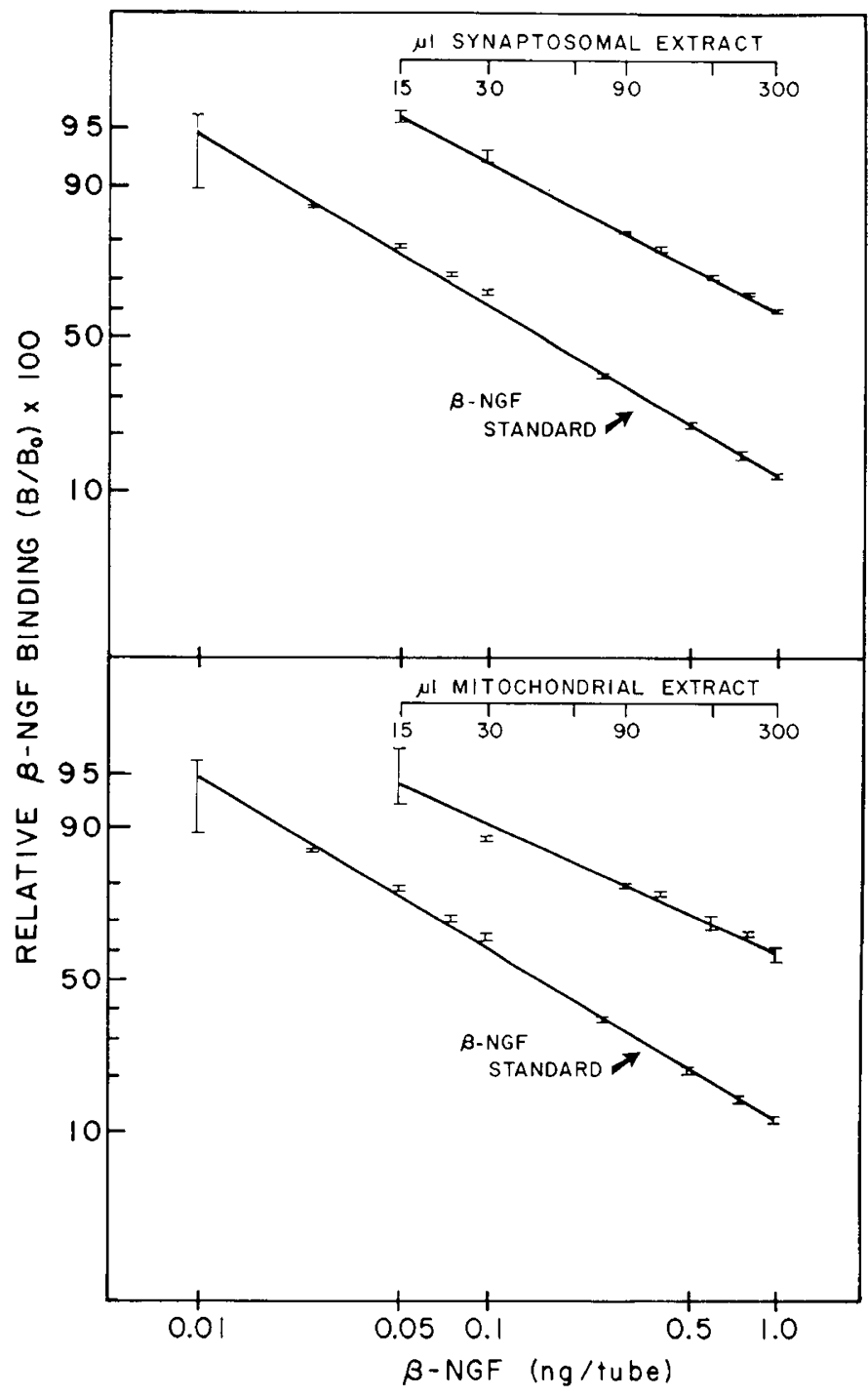

Fig. 2. $\beta$ NGF immunoreactivity in synaptosomal and mitochondrial fractions of mouse cerebral cortex. Synaptosomal $\left(P_{2} B\right)$ and mitochondrial $\left(P_{2} C\right)$ fractions were isolated from 26-day-old mouse cerebral cortex as described in Figure $1 A$. Synaptosomal and mitochondrial extracts were prepared in phosphate-buffered saline buffer as detailed in text. Varying amounts of the extracts were assayed for $\beta$ NGF concentrations. Note: the regression lines for displacement by synaptosomal extracts were consistently parallel to the $\beta$ NGF standard. The regression lines for mitochondrial extract were not parallel statistically. The slope values are given in the text.

dures, certain artifacts, such as exogenous uptake or redistribution among various intracellular compartments cannot be ruled out. To evaluate the extent of artifact, $\beta$ NGF concentrations were measured in synaptosomal fractions isolated from cerebral cortices of 21-day-old mice which received intraventricular injections of purified $\beta$ NGF. Exogenous administration of either 5 ng (six times whole brain $\beta$ NGF content) or $100 \mathrm{ng}$ (120 times whole brain content) $\beta$ NGF $16 \mathrm{~h}$ prior to sacrifice did not appreciably increase synaptosomal $\beta$ NGF concentrations (Fig. 4).

The relative amounts of $\beta$ NGF in whole brain, cortex, and synaptosomal extracts of 26-day-old mice are shown in Figure 5. The $\beta$ NGF concentrations, expressed per milligram synaptosomal protein, were higher in SEs than in whole brain or cortex extracts. $\beta$ NGF concentrations in synaptosomal extracts of mouse cerebral cortex measured during various stages of development are shown in Figure 6. The mean synaptosomal $\beta$ NGF concentration was highest on postnatal day 12 and the content

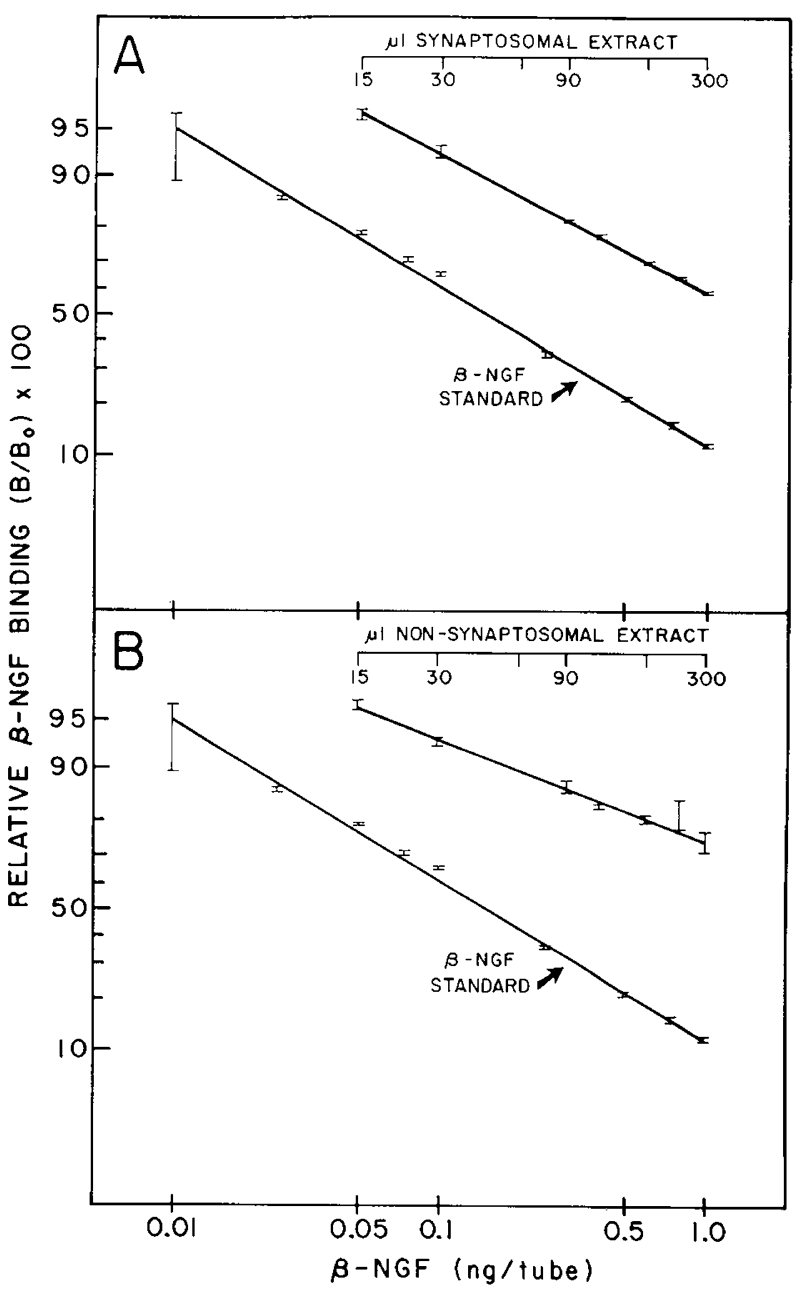

Fig. 3. $\beta$ NGF immunoreactivity in synaptosomal versus nonsynaptosomal fractions. Pooled cerebral cortices of 26 day old mice were divided into two halves. One-half was homogenized $(10 \% \mathrm{w} / \mathrm{v})$ in 0.32 $\mathrm{M}$ sucrose and the other in $0.25 \mathrm{M}$ sucrose. Both homogenates were identically processed as in Figure $1 A$. $\beta$ NGF content was assayed in varying amounts of the extracts. $A$ shows synaptosomal extract and $B$ shows nonsynaptosomal extract. Only synaptosomal extract $(A)$ produced a displacement line parallel to standard $\beta$ NGF. Slope values are given in the text.
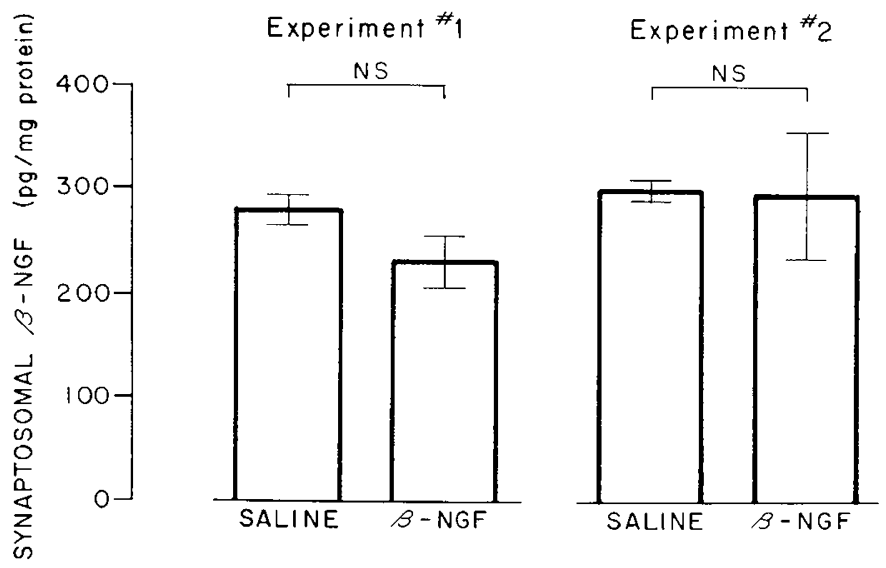

Fig. 4. Synaptosomal $\beta$ NGF concentrations following intraventricular injection of purified $\beta$ NGF. Groups of 21-day-old mice (15 animals in each group) were injected intraventricularly with: a) $3 \mu$ l volume of sterile saline, b) $5 \mathrm{ng} \beta \mathrm{NGF} /$ mouse in $3 \mu \mathrm{l}$ saline (experiment 1) or c) $100 \mathrm{ng}(\beta \mathrm{NGF} /$ mouse) in $3 \mu \mathrm{l}$ saline (experiment 2 ). Animals were sacrificed $16 \mathrm{~h}$ after the injection. Cerebral cortices were removed, pooled (five cortices/pool) and processed for synaptosomal isolation as described in Figure $1 A$. See text for other details. 
decreased with increasing age. No significant differences were seen between days 21 and 32 . In contrast to synaptosomal $\beta$ NGF concentration, the protein content of SEs was unchanged from day 12 to 32 .

Neurite outgrowth response to $S E$. To assess the biological activity of the synaptosomal $\beta \mathrm{NGF}, 100$ mouse cerebral cortices from 12-day-old animals were processed as described in Figure $1 A$. Synaptosomal fractions were extracted in RPMI-1640 buffer

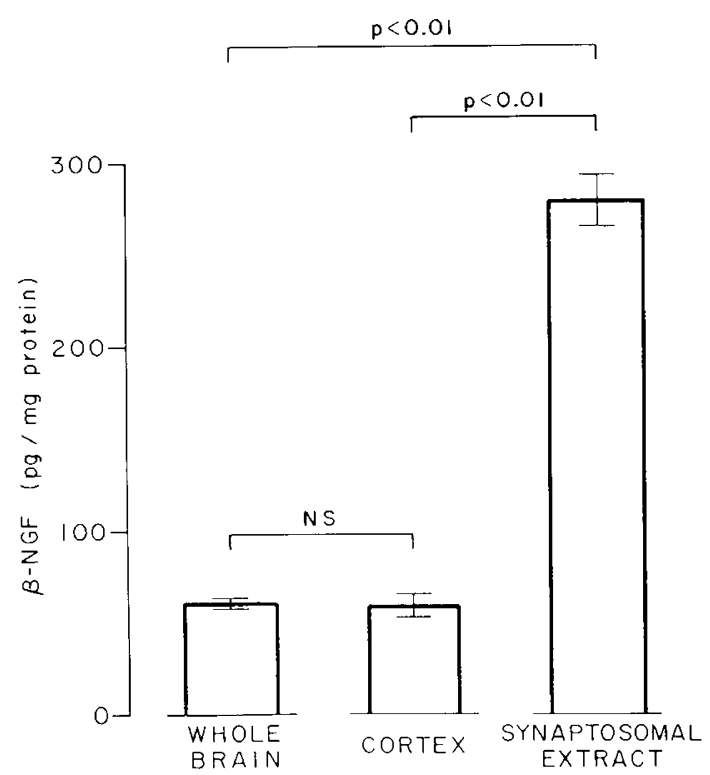

Fig. 5. The relative distribution of $\beta$ NGF in 26-day-old mouse brain. Extracts of whole brain, cerebral cortex, and synaptosomes of cerebral cortex were prepared in phosphate buffered saline as described in the text. $\beta$ NGF concentrations were determined by RIA. and concentrated by pressure dialysis against the same buffer using Diaflo ultrafiltration membrane 10YM (Amicon Corporation, Lexington, MA). $\beta \mathrm{NGF}$ concentrations equivalent to $4 \mathrm{~g}$ original cerebral cortex (wet weight) were added to wells containing PC-12 cells $\left(1 \times 10^{4}\right.$ cells $\left./ \mathrm{ml}\right)$. The neurite outgrowth response was observed after a 24 -h incubation period (Fig. 7). The positive neurite outgrowth response due to synaptosomal $\beta \mathrm{NGF}$ was completely inhibited by $\beta$ NGF-antibody (Fig. $7 \mathrm{D}$ and $H$ ). Three independent isolation procedures consistently yielded positive neurite response in the PC-12 cell bioassay system. In all cases neurite outgrowth was accompanied by $\mathrm{PC}-12$ cell aggregation, but $\beta \mathrm{NGF}$ antibody had no influence on the cell-cell aggregation.

\section{DISCUSSION}

We chose cerebral cortex for our study since this region has been reported recently to contain NGF-responsive cholinergic neurons both in neonatal and adult animals (10). The protocol described in Figure $1 A$ routinely yielded good synaptosomal preparations as judged by electron microscopic and morphological criteria. We avoided repeated washings and rehomogenization procedures hoping to minimize artifacts.

For synaptosomal $\beta$ NGF quantification we used a newly developed $\beta$ NGF polyclonal antiserum consisting of at least two high affinity antibodies. The assay is sensitive to $16-21 \mathrm{pg} \beta \mathrm{NGF} /$ tube. Synaptosomal extracts produced displacement lines in the RIA parallel to standard $\beta$ NGF suggesting the presence of $\beta$ NGFlike immunoreactive material. Both mitochondrial fractions and 0.8 and $1.2 \mathrm{M}$ sucrose interface fractions, following initial homogenization of cerebral cortex in $0.25 \mathrm{M}$ sucrose, produced nonparallel displacement in the $\beta$ NGF-RIA. The significance of nonparallel displacement needs further investigation. Whether this material represents the high molecular weight form of $\beta \mathrm{NGF}$ (pro- $\beta$ NGF) or a breakdown product of $\beta$ NGF remains to be clarified. Moreover, we did not analyze the purity of the non-
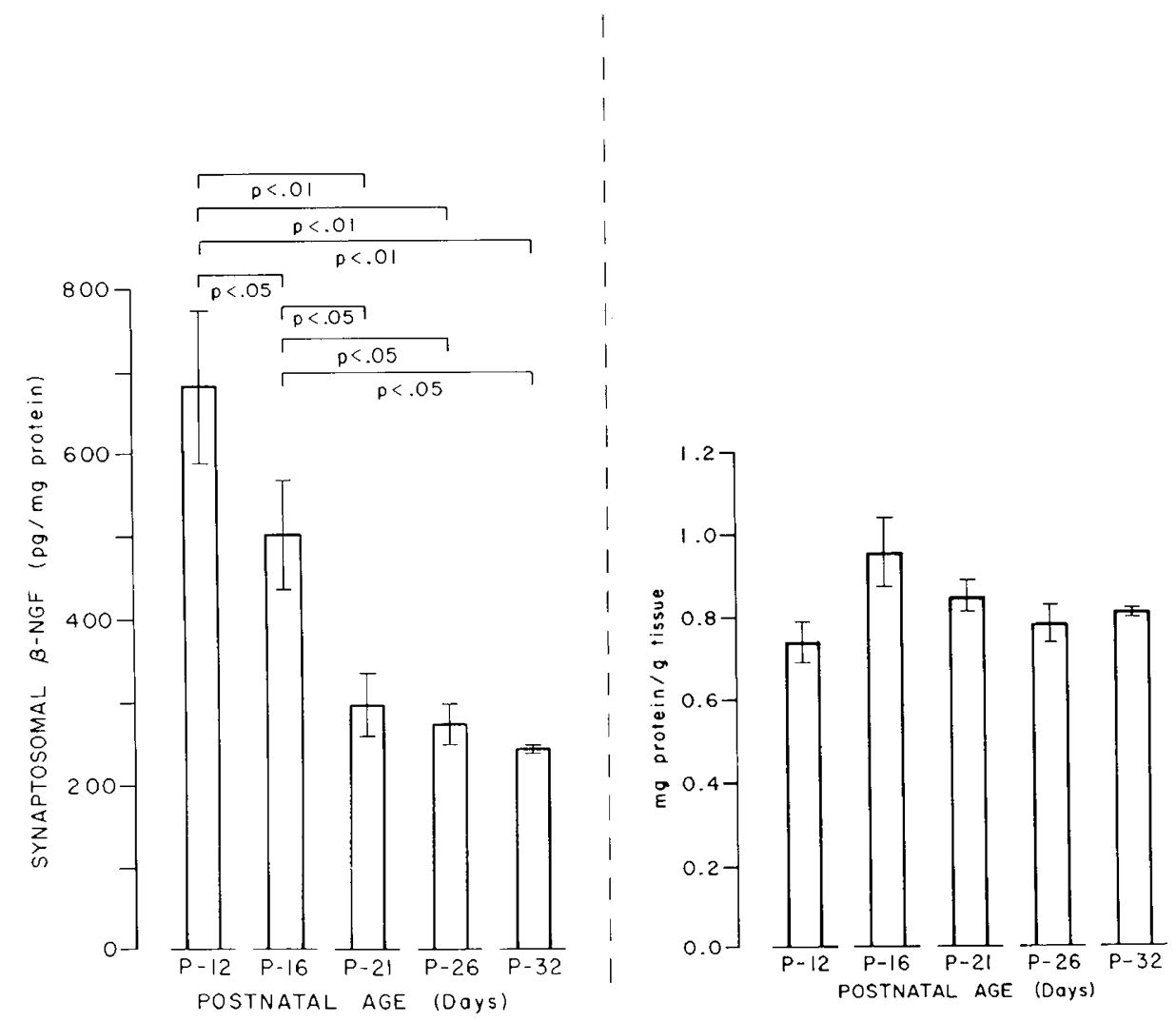

Fig. 6. Developmental profiles of synaptosomal $\beta$ NGF (left $)$ and protein concentrations ( right). Cerebral cortices removed from mice of various postnatal ages (day 12,16,21,26, and 32) were processed for synaptosomal isolation as detailed in Figure 1A. Synaptosomal extracts were assayed for $\beta \mathrm{NGF}$ concentrations by RIA. Protein content in the extracts were measured by the method of Lowry et al. (25). See text for other details. 

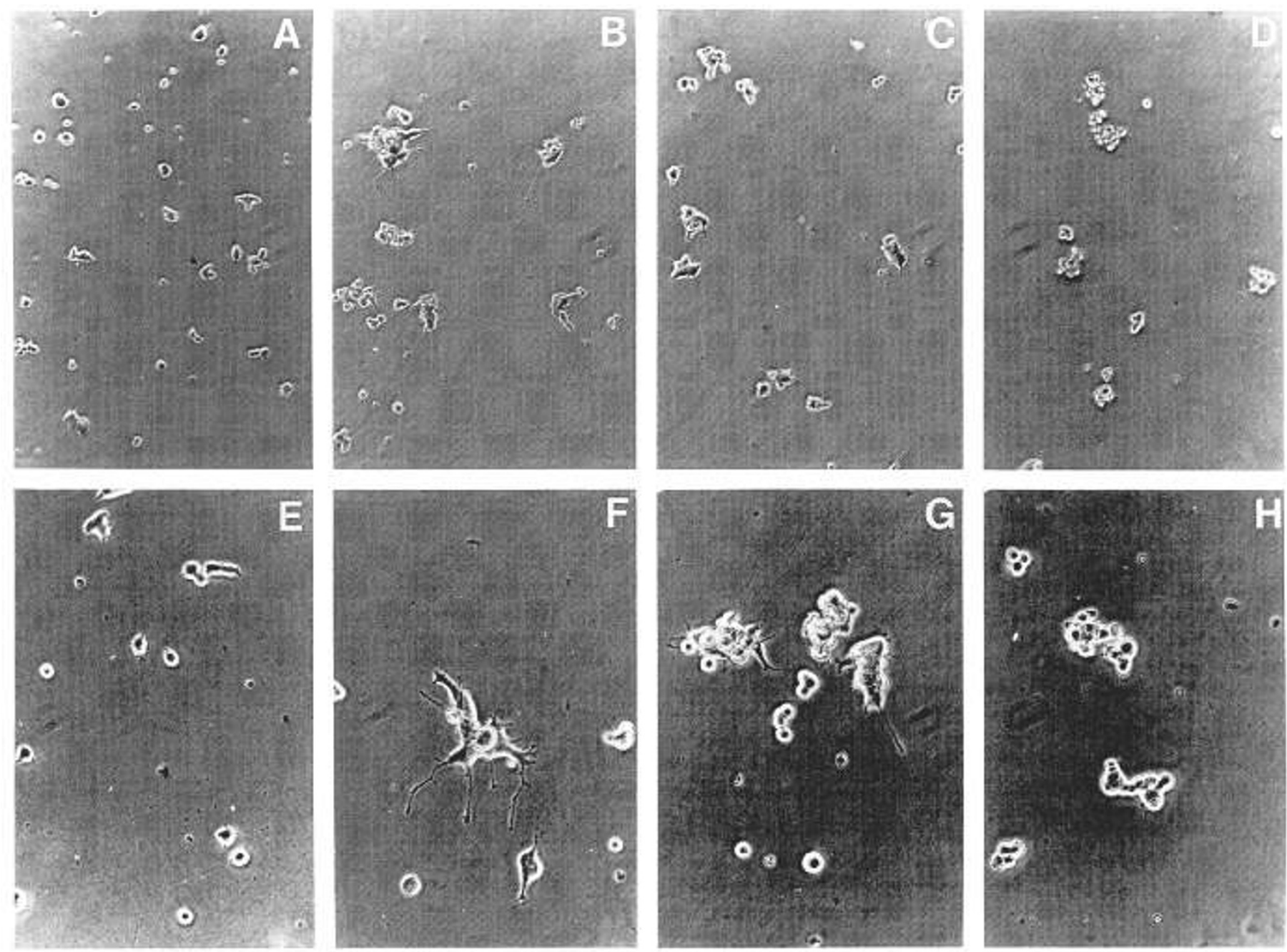

Fig. 7. PC-12 bioassay for SE. Synaptosomal fractions isolated from 12-day-old mouse cerebral cortices were extracted in RPMI-1640 buffer and pressure dialyzed against the same buffer, as indicated in the text. Concentrations equivalent to $4 \mathrm{~g}$ original cortex wet weight were added to culture dishes containing $1 \mathrm{ml}$ of PC-12 cell suspension $\left(2 \times 10^{4}\right.$ cells). To assess the specificity of $\beta \mathrm{NGF}$-induced neurite outgrowth, purified $\beta \mathrm{NGF}$ antibody was included in companion dishes. The neurite response was recorded after $24 \mathrm{~h}$. Cells were photographed using a phase contrast microscope. Additions: none $(A, E)$; SEs of two independent preparations $(B, C, F, G)$; SE in the presence of $500 \mu \mathrm{g}$ of purified $\beta \mathrm{NGF}$ antibody $(D$, $H$ ). Top row $A-D=\times 100$ magnification, bottom row $E-H=\times 200$ magnification.

synaptosomal fractions. Reports of the presence of NGF-specific receptors in synaptosomal fractions $(21,22)$, as well as specific retrograde axonal transport in CNS $(14,15)$, prompted us to examine the extent of any artifact which might be induced by receptor binding in the synaptosomal preparations. Even when large amounts of $\beta \mathrm{NGF}$ (six to 10 times the whole brain $\beta$ NGF concentration on day 21 ) were given intraventricularly, we were unable to alter the endogenous synaptosomal $\beta \mathrm{NGF}$ concentrations. This result suggests that $\beta N G F$ is not freely diffusable from the intraventricular space to other brain regions and that the endogenous synaptosomal $\beta$ NGF immunoreactivity did not represent contamination occurring during the tissue processing procedures. Preliminary studies revealed that the addition of purified $\beta \mathrm{NGF}$ at a concentration of $5 \mathrm{ng} / \mathrm{ml}$ in a $10 \%$ cortical homogenate prepared in $0.32 \mathrm{M}$ sucrose did not influence the concentration of endogenous synaptosomal $\beta \mathrm{NGF}$ concentration.

Small, but significant, concentrations of $\beta N G F$ were detected in whole brain, cortex, and synaptosomal fractions. The $\beta$ NGF concentrations reported herein for cerebral cortex of 21-day-old mice were significantly lower than the levels reported earlier from our laboratory by Walker et al. (31). The difference presumably is attributable to methodological variations. In the present study we used a $145,000 \mathrm{~g}$ supernatant for $\beta$ NGF quantification while Walker et al. (31) used a 25,000 g supernatant fraction. In addition, the purified $\beta$ NGF used in the present study was prepared by the method of Mobley et al. (26), as modified by Chapman et al. (27), and was used for immunization, iodination, and as reference standard. Also, we used a newly developed higher affinity antiserum for the RIA system in the present study. Finally, we have taken special precautions to prevent NGF contamination from the submandibular gland, a tissue which contains relatively high concentrations of $\beta$ NGF even during the weanling stage.

The relatively high concentration of $\beta$ NGF in synaptosomal fractions, as opposed to whole brain or cerebral cortex, demonstrates that this growth factor is not uniformly distributed in brain tissue. Studies of $\beta$ NGF concentrations in SEs during various stages of development showed that the concentrations of endogenous synaptosomal $\beta \mathrm{NGF}$ is higher on day 12 than at other ages investigated. We did not attempt to isolate synaptosomes from animals younger than 12 days since there is no morphological evidence for the existence of mature presynaptic nerve terminals in such young animals.

Synaptosomal extracts of 12-day-old mouse cortex consistently elicited neurite responses in the PC- 12 bioassay. Moreover, this neurite outgrowth response was completely inhibited by $\beta$ NGFantibody. Synaptosomal extracts also caused aggregation of the PC- 12 cells, but this aggregation was insensitive to $\beta$ NGF-anti- 
body. Further work is in progress to purify $\beta$ NGF immunoreactivity from synaptic extracts free of aggregation factor(s).

In conclusion, in the present study we detected subnanogram quantities of $\beta$ NGF in whole brain, cerebral cortex, and SEs of mouse cerebral cortex using a highly sensitive and specific $\beta$ NGFRIA system. $\beta$ NGF in similar concentrations has been reported recently in different regions of rat brain by Korsching and Thoenen (32). These investigators used a two-site RIA technique. In addition, Shelton and Reichardt (33) have reported detection of $\beta$ NGF-mRNA in mouse brain. Our results indicate that much of this $\beta$ NGF material in CNS is localized to presynaptic nerve terminals. Whether $\beta$ NGF is localized within specific nerve terminals and whether $\beta$ NGF performs any localized neuromodulator or neurotransmitter-like functions on the presynaptic side of the synapse remain interesting aspects for further study.

Acknowledgments. The authors thank Miss H. Kim for synaptosomal isolation, and Dr. Hideo Itabashi and Miss Marilyn Jones for their help with the electronmicroscopy.

\section{REFERENCES}

1. Bradshaw RA 1978 Nerve growth factor. Ann Rev Biochem 47:191-216

2. Varon S, Adler R 1981 Trophic and specifying factors directed to neuronal cells. Adv Cell Neurobiol 2:115-163

3. Levi-Montalcini R 1968 Nerve growth factor. Physiol Rev 48:534-569

4. Levi-Montalcini R, Angeletti PU 1963 Essential role of nerve growth factor in survival and maintenance of dissociated sensory and sympathetic embryonic nerve cells in vitro. Dev Biol 7:653-659

5. Cohen S 1960 Purification of a nerve growth promoting protein from the mouse salivary gland and its neurotoxic antiserum. Proc Natl Acad Sci USA 46:302-311

6. Levi-Montalcini R, Booker B 1960 Destruction of the sympathetic ganglia in mammals by an antiserum to a nerve growth protein. Proc Natl Acad Sci USA 46:384-391

7. Zaimi E, Knight J 1972 Nerve growth factor: Stimulation of regenerative growth of central noradrenergic neurons. Science 175:1251-1253

8. Bjorklund A, Stenevi U 1972 Nerve growth factor: stimulation of regenerative growth of central noradrenergic neurons. Science 175:1251-1253

9. Bjerre B, Bjorklund A, Stenevi U 1974 Inhibition of regenerative growth of central noradrenergic neurons by intracerebrally administered anti-NGF serum. Brain Res $1-18$

10. Gahn H, Hefti F, Heumann R, Schwab ME, Thoenen H 1983 NGF-mediated increase of choline acetyltransferase (CHAT) in the neonatal rat forebrain: evidence for a physiological role of NGF in the brain. Dev Brain Res 9:4552

11. Mobley WC, Rutkowski JL, Tennekoon G, Buchanan K, Johnston MV 1985 Choline acetyltransferase activity in striatum of neonatal rats increased by nerve growth factor. Science 229:284-287

12. Hefti F, Dravid A, Hartikka J 1984 Chronic intraventricular injections of nerve growth factor elevate hippocampal choline acetyltransferase activity in adult rats with partial Septo-Hippocampal lesions. Brain Res 293:305-311

13. Honegger P Lenoir D 1982 Nerve growth factor (NGF) stimulation of cholin- ergic telenecephalic neurons in aggregating cell cultures. Dev Brain Res 3:229-238

14. Schwab ME, Otten U, Agid Y, Thoenen H 1979 Nerve growth factor (NGF) in the rat CNS. Absence of specific retrograde axonal transport and tyrosine hydroxylase induction in locus coeruleus and substranta nigra. Brain Res 168:473-483

15. Seiler M, Schwab ME 1984 Specific retrograde axonal transport of nerve growth factor (NGF) from neocortex to nucleus Basalis in the rat. Brain Res 300:33-39

16. Johnson DG, Gorden P, Kopin IJ 1971 A sensitive radioimmunoassay for $7 \mathrm{~S}$ nerve growth factor antigens in serum and tissues. J Neurochem 18:23552362

17. Hendry IA 1972 Developmental changes in tissue and plasma concentrations of the biologically active species of nerve growth factor in the mouse, by using a two-site radioimmunoassay. Biochem J 128:1265-1272

18. Walker P, Weichsel ME Jr, Fisher DA, Gud S, Fisher DA 1979 Thyroxine increases nerve growth factor concentration in adult mouse brain. Science 204:427-429

19. Rosenberg MB, Grossman MA, Breakefield XO 1984 Artifactual presence of $\beta$-nerve growth factor in adult mouse brain. Brain Res 295:35-40

20. Carstairs JR, Edwards DC, Pearce FL, Vernon CA, Walters SJ 1977 Immunogenic contaminants in mouse nerve factor. Eur J Biochem 77:311-317

21. Szutowicz A, Frazier W, Bradshaw R 1976a Subcellular localization of nerve growth factor receptors. Thirteen day chick embryo brain. J Biol Chem 251:1516-1523

22. Szutowicz A, Frazier W, Bradshaw RA 1976b Subcellular localization of nerve growth factor receptors. Developmental correlation in chick embryo brain J Biol Chem 251:1524-1528

23. Gray EG, Whittaker VP 1962 The isolation of nerve endings from brain. An electron microscopic study of cell fragments derived by homogenization and centrifugation. J Anat 96:79-87

24. Levitan IB, Mushynski WE, Ramirez G 1972 Highly purified synaptosomal membranes from rat brain. J Biol Chem 247:5376-5381

25. Lowry OH, Rosebrough NJ, Farr AL, Randall RJ 1951 Protein measurement with the Folin phenol reagent. J Biol Chem 193:263-275

26. Mobley WC, Schenker A, Shooter EM 1976 Characterization and isolation of proteolytically modified nerve growth factor. Biochemistry 15:5543-5552

27. Chapman CA, Banks BE, Carstairs JR, Pearce FL, Vernon CA 1979 The isolation of immunologically pure material from the mouse submandibular gland. FEBS Lett 105:341-344

28. Greenwood FL, Hunter WM, Glover JS 1962 The preparation of ${ }^{131}$ I-labeled human growth hormone of high specific radioactivity. Biochem $J$ 89:114124

29. Grueters A, Lakshmanan J, Tarris R, Alm J, Fisher DA 1985 Nerve growth factor in mouse milk during early lactation: lack of dependency on submandibular salivary glands. Pediatr Res 19:931-977

30. Walker P, Weichsel ME Jr, Guo SM, Fisher DA 1982a Radioimmunoassay for mouse nerve growth factor (NGF) effects of thyroxine administration on tissue NGF levels. Brain Res 186:331-341

31. Walker P, Weichsel ME Jr, Eveleth D, Fisher DA 1982b Ontogenesis of nerve growth factor and epidermal growth factor in submaxillary glands and nerve growth factor in brains of immature mice correlation with ontogenesis of serum levels of thyroid hormones. Pediatr Res 16:520-524

32. Korsching S, Thoenen H 1984 Regulation of nerve growth factor synthesis in target tissues of the peripheral and central nervous system. Soc Neurosci Abstr 10:307.6:1056

33. Shelton DL, Reichardt LF 1984 Expression of the $\beta$-nerve growth factor gene correlates with the density of sympathetic innervation in effector organs. Proc Natl Acad Sci USA 81:7951-7955 